\title{
Alimentos tradicionales andinos, turismo y lugar: definiendo la nueva geografía de la Quebrada de Humahuaca (Argentina) ${ }^{1}$
}

\author{
Mariana Arzeno $^{2}$ y Claudia Alejandra Troncoso 3
}

\begin{abstract}
RESUMEN
Existe en la actualidad un creciente interés por el consumo de productos alimenticios cuyos principales atractivos se vinculan con su distinción asociada a un origen geográfico y cultural determinado. Esto trae a un primer plano un tema de interés para la Geografía: los procesos actuales de construcción de lugares vinculados con las nuevas prácticas de consumo de alimentos (ya sean cotidianas o asociadas al turismo), como formas de valorización de diferencias geográficas y culturales. A partir de un estudio de caso (la Quebrada de Humahuaca, noroeste de Argentina), este artículo examina el proceso de puesta en valor de las especificidades del lugar en relación con la producción y consumo de productos y preparaciones típicas del mundo andino. Dicho análisis contempla los procesos más amplios que inciden en las transformaciones recientes en el lugar (tanto en el plano material como simbólico), así como los múltiples actores que intervienen en ellas.
\end{abstract}

Palabras clave: Alimentos tradicionales andinos, turismo, lugar, Quebrada de $\mathrm{Hu}-$ mahuaca.

\begin{abstract}
In recent years we experience a growing interest in the consumption of distinctive food products associated to particular geographical and cultural origins. This highlights an interesting topic from a geographical perspective: the current process of building places based on food consumption practices (either by local resident or tourists) associated to the recovery of cultural and geographical differences. This article examines the valorization process of place's specificities in relation to the production and consumption of typical Andean products and preparations focusing on what is happening at a specific place: Quebrada de Humahuaca, Northwestern Argentina. This analysis includes the broader material and symbolic processes that transform this place and the multiple actors involved in them.
\end{abstract}

Key words: Traditional andean food, tourism, place, Quebrada de Humahuaca.

1 Proyecto PICT N 00188 (FONCyT-Agencia), UBACyT F056, PICT N² 25353 (FONCyT-Agencia) y UBACYT F044. Las autoras agradecen la lectura y sugerencias de Rodolfo Bertoncello. Artículo recibido el 3 de mayo de 2011, aceptado el 9 de enero de 2012 y corregido el 16 de enero de 2012.
2 CONICET, Programa de Economías Regionales y Estudios Territoriales del Instituto de Geografía de la Universidad de Buenos Aires (Argentina). E-mail: mariana.arzeno@conicet.gov.ar

3 CONICET, Instituto de Geografía de la Universidad de Buenos Aires (Argentina). E-mail: claudia.troncoso@conicet.gov.ar 
Existe en la actualidad un creciente interés por el consumo de productos alimenticios cuyos principales atractivos se vinculan, por un lado, con su distinción asociada a un origen geográfico y cultural, y por otro, con algunas condiciones ligadas a las formas en que son elaborados.

El interés por estas cuestiones desde el ámbito académico ha generado una importante producción de literatura sobre (i) los sistemas alternativos de producción y distribución de alimentos vinculados con la producción de specialities que condensan cultura y lugar y sobre las que recaen iniciativas de políticas orientadas al desarrollo rural endógeno (Ilbery et al., 2005; Maye \& Ilbery, 2006; Watts et al., 2005; Parrot et al., 2002; Feagan, 2007; Ilbery \& Kneafsey, 1998; Bérard et al., 1996) y (ii) las nuevas formas de consumo turístico de alimentos exóticos, tradicionales, artesanales y las preparaciones típicas de un lugar con el surgimiento de nuevas modalidades turísticas que buscan diferenciarse del turismo masivo (Cook \& Crang,1996; Bessière, 1998; Armesto López y Gómez Martín, 2004; Schlüter, 2006; Germann Molz, 2007; Everett, 2009; y el número especial de la revista Pasos. Turismo y patrimonio cultural de 2008, entre otros).

Lo anterior trae a un primer plano un tema que ha estado fuertemente presente en la Geografía, y las ciencias sociales en general, como lo es la importancia que la diferenciación geográfica adquiere en la actualidad (Harvey, 1998; Massey, 1991; Agnew, 1987). En efecto, en las últimas décadas han sido estudiados los procesos de valorización de las especificidades geográficas, de lo local, de la reproducción y visibilización de la diferencia, así como aquellos orientados a producir especificidades locales buscando hacer competentes a los lugares en el escenario mundial. En vinculación con esto, se afirma, entre otras cosas, que el lugar no pierde significación como consecuencia de la mayor movilidad social y geográfica, así como que la diferencia espacial implica desigualdad entre lugares y por lo tanto ventajas y desventajas en la realización social y económica de individuos y organizaciones. El presente trabajo se inscribe en esta línea de indagación buscando comprender los procesos actuales de construcción de lugares, en este caso vin- culados con las nuevas formas de consumo y de producción de alimentos (y productos agrarios) como formas de valorización de diferencias geográficas y culturales.

A partir de un estudio de caso (la Quebrada de Humahuaca, tradicional área agrícola y ganadera en el noroeste de la Argentina), este artículo examina el proceso de puesta en valor de las especificidades del lugar en relación con la producción y consumo de productos y preparaciones típicas del mundo andino. Se trata de productos como la quinoa, el yacón, el amaranto, la papa andina, la oca, la carne de llama, que han sido desarrollados por la población campesina de ascendencia indígena de la Quebrada, pero cuya producción venía disminuyendo en las últimas décadas debido a su reemplazo por otras producciones de mayor demanda en el mercado regional (como flores y hortalizas) y a cambios en las costumbres alimenticias de esta sociedad.

Sin embargo en la última década recae un creciente interés sobre los productos típicos andinos, pasando a ser objetos de promoción tanto desde los organismos públicos, las ONG y organizaciones de productores que orientan su accionar al desarrollo agropecuario (Arzeno, 2007; 2008), como desde los actores vinculados al turismo, en particular a partir del reconocimiento de la Quebrada como Patrimonio de la Humanidad por parte de la UNESCO en el año 2003 (Troncoso, 2008a; 2008b).

El objetivo de este trabajo, entonces, es comprender el proceso de construcción de la Quebrada de Humahuaca como un lugar agrario y turístico atendiendo a las especificidades que toma la producción y consumo de alimentos asociados al mundo andino ${ }^{4}$.

\footnotetext{
4 Este trabajo recoge algunos resultados de dos investigaciones en profundidad sobre las transformaciones recientes en la Quebrada de Humahuaca. Ambas investigaciones incluyeron las tareas de relevamiento, sistematización, análisis e interpretación de información empírica proveniente de documentación variada (información estadística elaborada por distintos organismos públicos, folletos elaborados por las asociaciones de productores, materiales de promoción turística de distintos momentos históricos elaborados desde la esfera pública, guías
} 
Luego de analizar algunos procesos de cambio actuales que vinculan producción de alimentos, cultura, lugar y desarrollo local y de introducir las formas de promoción del consumo de productos andinos en el país, el trabajo se focaliza en el análisis de la construcción de los productos andinos como atractivo turístico y la recuperación de su producción como estrategia para el desarrollo agropecuario de la Quebrada. Luego se realiza una interpretación del proceso analizado a la luz de algunas conceptualizaciones sobre el lugar, destacando, en particular, las distintas dimensiones involucradas en el proceso de construcción y valorización de la Quebrada como lugar turístico y agrario perteneciente al mundo andino. Por último se presentan unas reflexiones finales.

\section{Productos agrarios, culturas y lugares en los procesos actuales de producción y consumo}

En las últimas décadas del siglo $X X$ se asiste a una serie de transformaciones en las formas de producción y consumo. Sucintamente, la producción de bienes estandarizados orientada a un mercado de consumo masivo existente hasta ese momento, comienza a ser acompañada de la progresiva consolidación de una producción de bienes orientados a segmentos cada vez más diferenciados de la demanda. Teniendo en cuenta este contexto, el análisis y las reflexiones realizados en este punto se refieren específicamente a la producción y consumo de alimentos que dan cuenta del papel del lugar y la diferenciación geográfica en el contexto actual.

\section{Los cambios en la producción y el consumo de alimentos}

El sistema agroalimentario moderno consolidado hacia mediados del siglo XX se

turísticas, artículos en revistas y periódicos, etc.) así como entrevistas realizadas a los productores, a los técnicos, representantes de organismos y programas públicos, funcionarios del gobierno provincial, empresarios turísticos y vecinos de las localidades quebradeñas. caracterizó, entre otras cosas, por la creciente desconexión de la producción agrícola (estandarizada y dirigida al mercado de consumo masivo), de su procesamiento y distribución. Una de las consecuencias de este proceso fue el distanciamiento de la práctica social del consumo de alimentos, de su producción como actividad geográfica y socialmente "localizada" (Ilbery et al., 2005).

En las últimas décadas del siglo XX el mercado agroalimentario experimenta una segmentación que se expresa en el mantenimiento de un consumo de productos masivos pero acompañado del surgimiento (entre sectores de ingresos medios y altos de áreas urbanas) de una demanda que exige ciertos estándares de calidad. Estos productos son de diverso tipo y se los identifica con distintas denominaciones (specialities, productos "de lujo", "alimentos de alto valor", "productos de nicho" $)^{5}$. Parte de esta demanda es "fabricada" por las grandes empresas que buscan elevar su rentabilidad, en un marco de creciente apertura de mercados y competencia (Lara Flores, 1998).

Pero las nuevas exigencias de calidad aparecen asociadas también a la propia evolución de los modos de vida y los comportamientos alimentarios. En este sentido, pueden observarse tres aspectos vinculados con los cambios en el consumo de alimentos:

a) la importancia otorgada a la calidad de los productos en lo que concierne a la salud, en dos aspectos fundamentales: la nutrición que pueden proporcionar y el valor calórico que poseen. Asociado a estos intereses se diversifica el consumo de productos orgánicos, sin agregados de sustancias químicas y producidos de manera artesanal, rescatando técnicas de producción que habían sido descartadas. Al mismo tiempo surgen movimientos que promueven ciertas formas de alimenta-

\footnotetext{
5 Lara Flores (1998: 76) engloba dentro de la denominación de productos de "lujo" aquellos que: (i) contienen un alto valor agregado; (ii) se destinan a un consumo suntuario; (iii) son de contraestación; (iv) reúnen nuevas características (precongelados, ensaladas preparadas, etc.); y (v) sirven para elaborar comidas "étnicas".
} 
ción en consonancia con nuevas formas de vida ${ }^{6}$.

b) el compromiso del consumidor frente a lo que consume, en relación con las condiciones en que los alimentos se producen o comercializan (Renard, 1999; Feagan, 2007). Así, se manifiesta una preocupación ecológica por los impactos sobre el medio ambiente que la producción de alimentos puede generar o las condiciones laborales, sanitarias y de seguridad en las que se producen. Esto se vincula con el surgimiento de nuevas ideas como aqueIlas vinculadas al consumo responsable y el comercio justo ${ }^{7}$.

c) el interés por el origen geográfico y el contexto cultural de lo que se consume. Los productos exóticos o elaborados con técnicas tradicionales, artesanales o en vías de desaparición, productos típicos de determinadas regiones que mantienen ciertas características propias, serán objeto de interés para los consumidores que buscarán incorporarlas a su vida cotidiana o consumirlos en los lugares de origen (Goodman \& Watts, 1994; Renard, 1999; Ilbery et al., 2005).

Interesa en particular destacar este último punto, en tanto aquí el acento se coloca en una fuerte vinculación entre alimento, cultura y geografía. En efecto, el "saber hacer" preservado a través de generaciones que interviene en la obtención de los alimentos, ciertas características físico-naturales del lugar (clima, suelo, disponibilidad de agua o sol), entre otros aspectos, formarán parte de sus particularidades y se traducirán en sus marcas distintivas (Feagan, 2007; Ilbery \& Kneafsey,

\footnotetext{
6 Ejemplo de esto es el movimiento Slow Food que pregona nuevas formas de consumo de alimentos tradicionales, locales, particulares que contrarrestan la estandarización que se asume como propia de la vida moderna actual.

7 Consumo responsable hace referencia a prácticas de adquisición de bienes que son asumidas como respetuosas del medio ambiente y las sociedades; comercio justo refiere a una propuesta de vinculación entre productores y consumidores que contemple formas de producción y comercialización aceptables para ambas partes.
}

$1998)^{8}$. De esta forma, cultura y naturaleza geográficamente localizadas otorgarán ciertas especificidades a los productos que no podrían ser reproducidas en otras condiciones.

Así, los cambios en el consumo se vinculan estrechamente con otros procesos sociales más amplios de valorización de lo natural y lo cultural asociados con los cuestionamientos a la globalización del sistema alimentario. En este sentido surgen movimientos alternativos que abogan por una revinculación de los alimentos con los lugares (Feagan, 2007), estimulando además su consumo. Estos procesos se enmarcan dentro de lo que algunos autores denominan "nuevas geografías de la producción y consumo de alimentos" (Ilbery et al., 2005) para dar cuenta de las transformaciones territoriales implicadas en ellos.

\section{Nuevas modalidades turísticas y consumo: en búsqueda de lo tradicional}

Naturaleza y cultura, especialmente aquellas consideradas en peligro de desaparición o de sufrir transformaciones irreversibles, se vuelven objeto de protección, visita y conocimiento. En este contexto los espacios rurales y los lugares de residencia de culturas no occidentales pasan a ser ámbitos altamente valorizados por las sociedades urbanas e industriales, por ejemplo, a través de las nuevas modalidades turísticas Ilamadas "alternativas" (por oposición al turismo de tipo masivo generalizado hasta fines del siglo XX). En efecto, estos lugares crecientemente comienzan a ser considerados como un depósito o reservorio donde encontrar valores preexistentes que han sido arrasados por la urbanización e industrialización modernas. Frente a ello, existe una idea generalizada que el turismo "rescata", "mantiene vivas" y puede ayudar a proteger a la cultura, la historia, las tradiciones, las costumbres y que sin la valoración que el turismo le otorga, dichos elementos se verían irremediablemente perdidos ${ }^{9}$, entre ellos, los

\footnotetext{
8 Los ejemplos sobre este tipo de asociación abundan; entre ellos se pueden mencionar los embutidos alheira de Portugal, los quesos tupí de España o los bra y raschera de Italia, entre muchos otros productos asociados a un área geográfica concreta y que reúnen una forma de elaboración particular (Bérard et al., 1996).

9 Así lo expresa el texto de la propuesta del Programa Argentino de Turismo Rural, que surgió como una
} 
alimentos típicos de cada lugar y las formas de producirlos y prepararlos. Así, el turismo estimularía la protección de estos rasgos, participando también en su reproducción.

Como acontece con otros bienes, el consumo de alimentos o preparaciones no se limita solamente a su ingesta, sino que contiene una dimensión simbólica que se apoya fuertemente en la consideración de productos o preparaciones como elementos que refuerzan formas de diferenciación geográfica y cultural (Cook \& Crang, 1996; Germann Molz, 2007; Feagan, 2007). En este sentido, lo que está en juego en el turismo culinario es una experiencia de vinculación con otras culturas y otros lugares diferentes a aquellos que caracterizan o forman parte de la vida cotidiana de los consumidores (o que ellos reconocerían como propios). Y, en particular, en el turismo lo que prima es la experiencia de su consumo in situ, en contacto directo con las formas de producción y elaboración de estos alimentos y con quienes los producen, que lo diferencia claramente de otras formas de consumo de alimentos exóticos (por ejemplo, la oferta gastronómica en los lugares de origen de los turistas).

Como veremos más adelante, estas asociaciones entre productos/preparaciones, cultura y lugar son reproducidas por diferentes actores vinculados con estas prácticas de consumo que difunden esta idea en la que subyace una suerte de "reparto" en el que a cada lugar se lo asocia con un producto o preparación que le es propia, a la manera de un "mosaico cultural" (Cook \& Crang, 1996). Claramente esto, más allá de constituir un reconocimiento objetivo de correspondencias preexistentes, implica una participación activa de todos estos actores en la construcción

iniciativa conjunta de la Secretaría de Agricultura, Ganadería, Pesca y Alimentación de la Nación y la Secretaría de Turismo de la Nación en 2000: "La incorporación del turismo permite el mantenimiento de la conservación de los recursos con el fin de ser mostrados. El desarrollo del turismo sustentable puede abastecer necesidades económicas, sociales y estéticas, a la vez que mantiene íntegra la cultura y los procesos ecológicos. Este tipo de turismo puede proveer beneficios a generaciones presentes sin disminuir las posibilidades de obtención de beneficios a generaciones futuras" (SAGPYA-SECTUR, 2000: 5). de la identidad de cada uno de estos lugares, reproduciendo determinados imaginarios geográficos (Cook \& Crang, 1996).

Asimismo, y como parte de este proceso, los destinos se esfuerzan por ofrecer productos y preparaciones que formarán parte de sus atractivos turísticos y habilitarán distintas formas de comercialización de bienes (por ejemplo, aquellos envasados a modo de souvenir) y servicios (gastronómicos, fundamentalmente). De esta manera, esta valorización de alimentos generará transformaciones en los lugares: en ellos se redefine el conjunto de actividades productivas o se generan nuevas modalidades de producción, se definen áreas y actores vinculados a las nuevas formas de producir, se delimitan espacios de consumo y además se produce, reproduce o actualiza un imaginario geográfico que construye o refuerza ciertas asociaciones entre productos/preparaciones, cultura y lugar. Así, los productos alimenticios también contribuirán a redefinir la forma que adquiere la oferta turística en los destinos.

\section{El ámbito local como área de} intervención para el desarrollo y la revalorización de productos tradicionales

La valorización actual de lo local también se manifiesta en el campo de la intervención para el desarrollo (entre otros, de los ámbitos rurales). En efecto, durante la década de 1990 se impone, dentro de las recomendaciones y directrices de los organismos internacionales de financiamiento y de las agencias de desarrollo internacionales y nacionales, un nuevo enfoque que parte de considerar el ámbito local como espacio preferencial de inserción en una economía globalizada y como ámbito destacado para promover el desarrollo, fortalecer la ciudadanía, la articulación social y la solidaridad (Moreira Braga, 2002), a partir de la utilización del conjunto de recursos (económicos, culturales, político-institucionales o humanos) que constituyen su potencial y de la promoción de la articulación entre los actores locales públicos y privados (Vázquez Barquero, 1998) ${ }^{10}$.

\footnotetext{
10 Análisis detallados de los presupuestos teóricos que subyacen a estos enfoques pueden encontrarse en Moreira Braga (2002) y Manzanal (2007). Para una
} 
En ese marco, la revalorización de las producciones agropecuarias y las preparaciones culinarias reconocidas como tradicionales o típicas de un lugar, pasa a ser un aspecto de creciente consideración como "recurso potencial" de determinados territorios y disparadores de iniciativas orientadas al "desarrollo local", ya sea a través de la inserción en "mercados de nicho" o de su promoción como parte de los atractivos turísticos de un lugar.

En relación con la producción de alimentos, es en Europa donde comienzan a tomar auge distintas estrategias de valorización lo$\mathrm{cal} /$ regional de productos alimenticios (Maye \& Ilbery, 2006). En general se trata de producciones locales tradicionales que se revalorizan de forma comercial (como por ejemplo, los denominados "productos de la tierra"). Todo tipo de asociación cultural o geográfica que detenten estos productos así como la información que pueda proveerse sobre ellos (propiedades nutritivas, técnicas involucradas en su producción, condiciones de cultivo, relevancia cultural, formas de preparación, formas de consumo) redundarán en un valor agregado que repercutirá en el precio de los mismos y en las ganancias obtenidas de la comercialización de los productos (Cook \& Crang, 1996; Ilbery \& Kneafsey, 1998). Es así que comienzan a recibir mayor atención por parte del Estado en el marco de políticas de desarrollo rural que buscan 'relocalizar' la producción de alimentos (Bérard et al., 1996; Ilbery et al., 2005; Maye \& Ilbery, 2006).

En ese marco, empiezan a extenderse las reglamentaciones orientadas a proteger a estos productos, a la vez que se les reconoce su calidad, con sellos y etiquetas que garantizan su distinción (denominación de origen; indicación geográfica, entre otros). En general esta estrategia se orienta a exaltar la diferencia: (i) entre la calidad de los productos específicos y aquellos producidos masivamente; (ii) entre el anonimato geográfico de la procedencia del producto y su especificidad territorial; y (iii) en cuanto a la forma en que los alimentos son producidos -industrial versus

crítica sobre la asociación "lugar-comunidad" remitimos a Massey (1991). artesanal o tradicional- (Ilbery et al., 2005: 118). Si bien este no es un proceso nuevo, es en la década de 1990 que se multiplican esquemas que usan etiquetas, certificaciones o acreditaciones como forma de promover ciertos lugares o procesos de producción, o bien productos agrícolas o artesanales específicos (llbery et al., 2005: 118).

Situaciones similares se han manifestado en los últimos años en algunos países de América Latina, especialmente del área andina. La promoción de productos agrícolas o comidas tradicionales de distintos ámbitos geográficos forma parte de las políticas de promoción del desarrollo rural, en la actualidad enmarcados en el enfoque del "desarrollo territorial rural"11.

En este contexto, el auge de la gastronomía típica de cada lugar, por ejemplo, viene de la mano de la difusión del consumo (entre otros, turístico) de productos tradicionales que encuentra eco en el interés actual por ellos, tal como mencionamos en el punto anterior. Gastronomía y turismo se presentan así como actividades promotoras de la agricultura, en particular aquella encarada por pequeños productores, a quienes más fuertemente se los asocia con la preservación de productos, técnicas y saberes tradicionales en riesgo de extinción.

Desarrollo, pequeños productores y cultivos tradicionales se unen así en situaciones que incluyen desde la apuesta a nivel nacional de la gastronomía como "locomotora del desarrollo"12 hasta distintas iniciativas

\footnotetext{
${ }^{11}$ El Desarrollo Territorial Rural (DTR) es definido según uno de sus principales promotores (el RIMISP - Centro Latinoamericano de Desarrollo Rural) como "un enfoque de análisis y de política pública que se plantea el impulso de procesos simultáneos de transformación productiva y cambio institucional a escala de territorios rurales" (http://www.rimisp.org).

12 En un artículo reciente se plantea que en Perú, la cocina genera una cadena de valor que produciría más de 14 mil millones de dólares $(11,2 \%$ del PBI) en 2009. En este sentido la gastronomía es presentada como "la nueva locomotora del desarrollo del país, ya que arrastra a otros sectores como la agricultura, ganadería, pesca, agroindustria, mercados mayorista y de abasto, transporte de alimentos, turismo, fábricas de ollas y menaje" (Valderrama León, 2010: 7).
} 
de "desarrollo territorial rural con identidad cultural" promovidas desde las políticas públicas, que se basan en la promoción de alimentos como elementos identitarios del territorio y recursos potenciales para el desarrollo (Törey, 2010).

En síntesis, el interés reciente por algunos productos alimenticios geográfica y culturalmente específicos se encuentra así con ciertas formas de incentivo a la producción local, tradicional y a pequeña escala como dos caras de una misma moneda de este proceso más amplio de valorización de lo específico que caracteriza a las formas actuales de producción y consumo alternativos o exclusivos.

En lo que sigue nos abocaremos a las formas de valorización específica de los productos andinos, especialmente aquellos producidos y consumidos en la Quebrada de Humahuaca, para luego centrarnos en las características que asumió el proceso de construcción y valorización reciente de la especificidad geográfica de este lugar en el marco de las nuevas formas de producción y consumo de alimentos (en este caso productos andinos) y nuevas prácticas turísticas asociadas a ellas.

\section{Los productos andinos: el incentivo de su consumo a través de la promoción}

En los últimos años asistimos en la Argentina a un proceso de reconocimiento y revalorización de producciones tradicionales a las que se atribuye cualidades distintivas. Este proceso expresa los cambios en el consumo alimenticio de ciertos sectores sociales señalados en el punto anterior. En este contexto, la gastronomía que involucra productos típicos, saludables, de contenido cultural, etc., adquiere una importancia y una promoción antes desconocidas. Esto incluye de manera central a los productos y preparaciones culinarias andinas ${ }^{13}$.

13 Este tema ha sido abordado en la compilación de Álvarez (2008) donde se presentan trabajos que formaron parte del III Congreso de las Cocinas Regionales de los Países Andinos, en que participaron diversos actores provenientes del ámbito académi-
En efecto, asistimos a una promoción de este tipo de productos a través de medios variados. Una de las formas en que se pone de manifiesto es a través de guías turísticas y folletos que tienen la intención de promover la visita a destinos que, como la Quebrada de Humahuaca, ofrecen este tipo de productos y preparaciones vernáculas para disfrutar in situ. Pero también existen otras formas de promoción que han sido responsables de colocar a los cultivos andinos en el conjunto de opciones para el consumo de productos exóticos o novedosos (ya sean en destinos del mundo andino o fuera de él). Por ejemplo, revistas o páginas de Internet especializadas, programas televisivos de cocina y eventos gastronómicos ${ }^{14}$ contribuyen a dar a conocer estos productos a un público más amplio. Ejemplo de esto también son las exposiciones (donde los mismos productores y promotores se hacen presentes) y que constituyen un marco para reforzar aquellas ideas sobre la necesidad de rescatar productos considerados "representantes" de determinadas culturas y lugares ${ }^{15}$.

Asimismo, la promoción que se hace de los productos andinos a través de distintos medios recupera una serie de atributos hoy ampliamente valorizados entre ciertos secto-

co, empresarial, de organizaciones de productores, etc. Asimismo, una presentación sobre el interés por los productos tradicionales andinos en la Quebrada de Humahuaca ha sido realizada en el trabajo de Álvarez y Sammartino (2009).

14 Pueden mencionarse como ejemplo las revistas Cuisine \& Vins o Lugares; el ciclo televisivo "Cocina regional: Argentina" (conducido por la reconocida chef Dolli Irigoyen) emitido por el canal El Gourmet a partir de enero de 2004; las distintas ediciones de la exposición Caminos y Sabores que se realiza desde 2005 en Buenos Aires, el Seminario Gastronómico "El maíz en la alimentación andina", realizado en Salta en 2008, el Congreso Andino de Gastronomía también en esa ciudad (desde 2006), el Tercer Congreso de las Cocinas Regionales de los Países Andinos, Desde los Andes al Plata: sabor y saber (2007) que se realizó en Buenos Aires, entre otros.

15 Así queda expresado en la promoción que la revista Slow Argentina hiciera de la edición del Salón del Gusto de 2006, realizada en Turín: "estarán presentes productores argentinos de alimentos de calidad, pertenecientes a la Red de Comunidades y también se expondrán los productos de los Baluartes con sus peculiaridades territoriales y producciones campesinas, constituyendo un festival de los productos más particulares del planeta que corren peligro de perderse por olvido" (Slow Argentina, 2006: 5). 
res sociales, especialmente sectores medios y altos de zonas urbanas. Entre los atributos destacados se suele hacer referencia a:

a) sus propiedades nutritivas:

"Hoy, los nutricionistas han comprobado que, efectivamente, muchos de los ingredientes básicos de la cocina andina [...] aportan beneficios extraordinarios para la salud, derivados fundamentalmente del hábitat donde se cultivan los vegetales y donde viven los animales [...] Hoy, la quinua es tan valorada que muchos nutricionistas consideran que podría contribuir a paliar el hambre en las zonas más desfavorecidas del planeta y ser uno de los cultivos más promisorios del siglo $\mathrm{XXI}^{\prime \prime}$ (Clarín, 16/09/2007).

b) su riqueza biológica en términos de variedades de ciertas especies; la papa andina constituye el principal ejemplo:

"En el país hay más de cuarenta variedades de papas [...]. Pero nosotros comemos una sola, la Espunta, que en Europa se usa como alimento para los cerdos. Las papas andinas, que se cultivan acá, pueden ser blancas pero también violáceas o rojizas. $\mathrm{Y}$ tienen distintos sabores; algunas, incluso, son más dulces que la batata" ( $\mathrm{La}$ Nación (a), 5/08/2007).

c) las técnicas de producción agraria. Así, por ejemplo, suele destacarse el sistema de cultivo y riego propio de las áreas andinas que permitió el cultivo histórico de ciertas especies:

"En tierra árida y semiárida, todos estos cultivos fueron realizados en terrazas construidas por los pueblos originarios de la región. Se trata de andenes escalonados, sostenidos en la sierra por paredes, calzadas con piedras, por las que también se distribuía el riego" (Clarín, 09/04/2005).

d) un origen histórico y sagrado que remite a su consumo en épocas prehispánicas:

"Además ha habido una serie de cultivos que los conquistadores españoles dejaron de lado o incluso llegaron a prohibirlos por supersticiones o simplemente por ha- ber sido consideradas por los nativos de la zona como plantas sagradas. Tal es el caso de la Kiwicha y de la Quinua o de otros tubérculos no emparentados con la papa como la Oca o Papa lisa" (Folleto sobre el Museo de la Vida Campesina, CAUQueVa, ${ }^{16}$ 2006).

e) la asociación entre estos productos agrícolas, conocimientos tradicionales sobre su producción y ámbito geográfico de origen que van a repercutir en sus cualidades intrínsecas:

"La combinación de la altura (de 1500 m.s.n.m. hasta 3600 m.s.n.m.), clima y la sabiduría de sus antiguos habitantes ha dado como resultado la obtención de productos vegetales de incomparable sabor, aroma y color, que día a día se valoran más" (Sitio web CAUQueVa).

f) su valor patrimonial. En efecto, algunos cultivos y las técnicas que requieren para su producción formaron parte de los elementos presentados como rasgos distintivos de la Quebrada de Humahuaca, para justificar su declaración como Patrimonio de la Humanidad ${ }^{17}$ y uno de los aspectos de su promoción actual. Esta idea se retoma en las presentaciones que hacen los programas de recuperación de los cultivos andinos:

“...la idea es promover los cultivos andinos como parte de nuestro patrimonio, para que todos los jujeños, los argentinos, asuman esos tesoros que tenemos no sólo para que la gente los coma, sino para que los conozca y se apropie de ellos..." (De-

\footnotetext{
16 Se trata de la Cooperativa Agropecuaria y Artesanal Unión Quebrada y Valles, de pequeños productores, sobre la que nos referiremos más adelante.

17 Así, por ejemplo, uno de los argumentos que presenta el gobierno provincial para lograr la designación, afirma: "La Quebrada es el escenario de un establecimiento tradicional humano muy característico, sobre todo referido al uso de la tierra, de lo cual se han conservado evidencias arqueológicas, tecnológicas y paisajísticas desde los albores de la domesticación hasta el presente, así como por la pervivencia de una gran diversidad de cultivos andinos. Constituye un paisaje de sustentabilidad en el tiempo y en el espacio" (Gobierno de la provincia de Jujuy, 2002, p. 35).
} 
claración de Magda Choquevilca, coordinadora de campo del proyecto Cultivos Andinos, Jujuy Activa Turismo, 2007: 6).

Esta promoción de los productos andinos, además, estimulará la visita turística y su consumo en el lugar, formando parte central de la atractividad turística del mismo como sucede en la Quebrada de Humahuaca.

\section{Los productos andinos como parte del atractivo y de la oferta turística de la Quebrada}

Ciertos rasgos de la Quebrada de Humahuaca como los paisajes, la cultura, la historia, la presencia indígena, las diferentes formas de vinculación con la tierra que se sucedieron a lo largo del tiempo, conforman su retrato turístico que se completa con los productos y preparaciones culinarias andinas. Asimismo, el carácter patrimonial de estos elementos en la actualidad (y por ende la justificación de su rescate y protección) refuerza su atractividad turística y su valorización social, cultural y económica, constituyendo un elemento de peso que incentiva, como en el caso de todo bien considerado patrimonio, su protección y su disfrute por un público amplio.

En este contexto, el consumo de productos andinos se concibe como un complemento a la experiencia del lugar como destino turístico ${ }^{18}$. Una de las principales formas en que se realiza dicho consumo es a través de la oferta de servicios gastronómicos que brinda la Quebrada. Pero ¿qué características toma el consumo de estos alimentos?, ¿cuáles son las propuestas gastronómicas que los incluyen?, ¿quiénes definen la manera en que se consumen estos productos?, ¿cómo se tiene en cuenta al consumidor al ofrecer los distintos platos?

\footnotetext{
${ }^{18}$ En general los materiales de promoción turística presentan a los productos alimenticios o las preparaciones culinarias andinas como una de las tantas opciones en una visita turística. Una cartilla elaborada en 2006 por la Secretaría de Turismo y Cultura de la provincia de Jujuy clasifica sus atractivos turísticos en los siguientes rubros: patrimonio, turismo religioso, turismo cultural, turismo alternativo y sabores (en el que se enumeran algunas de las preparaciones gastronómicas norteñas).
}

La oferta gastronómica de la Quebrada incluye entre sus propuestas distintas preparaciones con los productos andinos que hoy pueden disfrutarse en varios restaurantes de las localidades quebradeñas. Dicha oferta es reciente; en efecto, la mayoría de los establecimientos gastronómicos de la Quebrada, con excepción de los de la localidad de Humahuaca, datan de la década de $2000^{19}$.

El crecimiento de la oferta gastronómica se vio acompañado de transformaciones en los productos y preparaciones ofertadas respecto de aquellas existentes en el pasado. Una guía turística de fines de la década de 1980, refiere a la cocina tradicional del noroeste argentino, y si bien se hace mención a los productos y formas tradicionales de prepararlos, muchos de los productos infaltables en un listado actual de cultivos andinos están ausentes ${ }^{20}$.

En términos generales, la nueva oferta de productos y preparaciones andinas combina en la actualidad algunas preparaciones tradicionales con otras novedosas. Los cambios que han sufrido estas preparaciones se orientan hacia la sofisticación y el refinamiento. A los tradicionales locros, empanadas, tamales, humitas y empanadillas de cayote se han sumado nuevos platos compuestos fundamen-

19 Durante el siglo XX se consolidó una forma de visitar la Quebrada en el día con tours organizados desde Salta y San Salvador de Jujuy. Humahuaca se constituyó en el punto de llegada de estas excursiones que allí se detenían a la hora del almuerzo y se dirigían a los locales gastronómicos de la localidad. La oferta gastronómica era casi inexistente en el resto de la Quebrada, al punto que una guía turística de 1998 afirma: "Para alojar existe una oferta confortable; sin embargo, para almorzar no existen muchas posibilidades. Hay opción de picnic" (Guía turística YPF, 1998: 268).

${ }^{20}$ Así se describe la cocina andina: "Desde hace probablemente algo más de un milenio, en los caseríos más remotos del NOA, adonde todavía se llega sólo a pie o a caballo, la cocina tradicional andina subsiste casi inalterada. Si la Coca-Cola llega a lomo de mula hasta caseríos a $4000 \mathrm{~m}$ de altura, aún hoy los granos son molidos a mano y tostados en vasijas de barro sobre las brasas. La base de la alimentación la constituyen el maíz, el poroto, la papa y el pimiento, que unidos a otra docena escasa de ingredientes -harina, zapallo, ají, sal, cebolla, grasa, manteca o aceite, alguita chaucha o zanahoria, hierbas aromáticas y lo que hay de carne- forman una gran variedad de platos regionales" (La Guía Pirelli. Argentina, 1989: 23). 
talmente con ingredientes tradicionales de la cocina del lugar en versiones adaptadas a las exigencias de los turistas. Algunos de los nuevos rasgos de esta oferta se vislumbran en las propuestas de los restaurantes locales, cuyos menús abarcan "sabores de la cocina tradicional con un toque gourmet" y cuyo resultado es "una puesta en valor de productos regionales tan nobles como la quinoa, las papas andinas, los diferentes maíces, las hierbas aromáticas y por supuesto la carne de llama y de cordero que el comensal puede disfrutar recorriendo una carta de exquisita variedad" (Carta Abierta Jujuy 2006: 9).

Ese "refinamiento" de la comida típica andina, se orienta a atender las demandas de los consumidores, a través de una adaptación a sus gustos. Así, los productos andinos se traducen en formas "consumibles" y se preparan en versiones o adaptaciones que combinan lo andino con aquellos detalles más conocidos para estos consumidores. Las preparaciones adoptan un estilo más familiar, a la vez que se sofistican respondiendo a la demanda por objetos culturales exóticos. En este sentido, un reconocido chef afirma que "...fuimos mezclando nuestros sabores hasta lograr un plato más afín al turista, tanto en nombre como en presentación" (Carta Abierta Jujuy, 2004: 7).

Así surge una oferta novedosa de comidas en restaurantes y eventos donde se hace presente la cocina andina, en las siguientes preparaciones: trigo mote cocido como risotto, chutney de locoto, quesito de cabra tibio en hojaldre, marinada de aceto y miel de caña, pernil de llama confit sobre zócalo de ragout de quinua, mousse de cayote sobre húmedo de chocolate, pochoclo de amaranto, risotto de quinua, lomo de llama con canasta de mote a la crema de curry o yacón flambeado al vino tinto, carne de llama a la naranja, a la provenzal, a la crema de choclo, al romero, al roquefort, al horno con papas andinas a la crema, a la pimienta negra, al oreganato, a la crema, al ajillo, o preparada como churrasco, empanadas, milanesas o brochet ${ }^{21}$.

\footnotetext{
21 Fuentes: La Nación (a) y (b), 5/08/2007; Hostnews; Hideout; Menú del restaurante El Colonial (Tilcara) relevado durante el trabajo de campo de enerofebrero de 2007.
}

Varios de estos productos protagonistas de la nueva oferta gastronómica, son ya básicos y se encuentran consolidados, tales como la carne de Ilama, las papas andinas y la quinoa. Sin embargo, en la actualidad, las propuestas se diversifican a partir de la incorporación de productos aun más novedosos y desconocidos, revitalizando esta oferta. Entre ellos se encuentran la kiwicha (amaranto), el yacón y el maíz morado que acompañan a los anteriormente mencionados y vuelven más sofisticadas las cartas de las cuales forman parte.

Estas traducciones necesarias para hacer más consumibles los productos locales van acompañadas de otros elementos que también ayudan a crear cierta ambientación como, por ejemplo, las vasijas de barro tradicionales del lugar en las que se sirven las preparaciones.

La nueva cocina inspirada en las comidas andinas tiene un conjunto de profesionales gastronómicos referentes que se identifican a sí mismos como los rescatistas de estos productos que habían quedado sumidos en el olvido, a raíz de su reemplazo por otros alimentos que pasaron a conformar la dieta andina. Ellos son reconocidos como los mentores de esta nueva cocina que investiga, rescata, experimenta con estos productos, pero que, por supuesto, se ajusta a las demandas de los consumidores conformando opciones novedosas para un público completamente ajeno a ellos ${ }^{22}$.

Sin embargo, a pesar de la revalorización de ciertos cultivos en el ámbito de la Que-

\footnotetext{
22 Uno de los chef referentes de esta nueva gastronomía andina explica la diferencia con la tradicional comida regional a la vez que da cuenta de su estrategia para crear un nuevo producto gastronómico: "Definido el lugar como restaurante de cocina de altura $[. .$.$] nos aclara que aquello que se entiende$ por cocina regional es más español y que la propuesta del José Balcarce es rescatar la gastronomía precolombina. Él se encarga de investigar, rescatar los platos andinos que sobrevivieron a la conquista y buscar sus materias primas. De esta manera, el amaranto, la quinoa, la llama y el api (trigo morado) vuelven al menú norteño, revalorizado por sus sabores y nutriente. [El chef] se encarga de viajar y conseguir los proveedores, principalmente de la zona de Tilcara y Humahuaca" (en Welcome Argentina).
} 
brada y su utilización en la gastronomía que se ofrece en el lugar, la demanda de estos productos se satisface solo parcialmente con la producción de la zona. En el caso de las papas andinas, estas provienen de algunas zonas altas de la provincia de Salta pero fundamentalmente de Bolivia. La carne de Ilama proviene en su mayor parte de Abra Pampa, una localidad puneña muy cercana y conectada con los mercados de localidades quebradeñas, donde las adquieren los empresarios gastronómicos. En el caso de la quinoa es frecuente que los empresarios adquieran aquella que proviene de Bolivia y se vende en el mercado de San Salvador de Jujuy a precios menores que en la Quebrada ${ }^{23}$. Esto forma parte de las estrategias de aprovisionamiento de los empresarios quebradeños, para quienes son frecuentes los viajes a dicha ciudad una o dos veces por semana para el abastecimiento de varios productos alimenticios (así como también envases, artículos de limpieza y otros que no se comercializan en el lugar).

Los locales gastronómicos de la Quebrada y otras localidades del país, así como los especialistas en culinaria andina, instalan y difunden productos y preparaciones que se suman al auge que en la actualidad tiene la gastronomía étnica, muchas veces también asociada a una alimentación más sana, por ser más artesanal en comparación con las formas industriales de cultivo y procesamiento de alimentos. Estas formas de difusión y de organización del consumo de los productos quebradeños a través de la oferta gastronómica a su vez refuerzan las asociaciones entre estos productos y la cultura quebradeña (o andina en términos generales), digna de ser conocida y experimentada a través de sus particularidades, entre ellas sus productos y platos considerados representativos del lugar. A su vez, esta explosión de la culinaria andi-

23 Una empresaria gastronómica de la localidad de Tilcara afirmaba que la carne de llama que utiliza en sus preparaciones proviene exclusivamente de aqueIla localidad puneña; asimismo, como en el caso de otros dos empresarios de la zona, comentó que si bien eventualmente compraba quinoa y papas andinas a una cooperativa quebradeña o a productores locales, en general le convenía adquirir esos mismos productos provenientes de Bolivia que se localizan en el mercado de Tilcara o en San Salvador de Jujuy (entrevistas personales, agosto 2008). na incentivó la recuperación de este tipo de cultivos, marginales en el panorama productivo quebradeño hasta hace pocos años y la creación de nuevas vías para su comercialización, como veremos a continuación.

\section{La producción agrícola tradicional en la Quebrada de Humahuaca y las estrategias de desarrollo}

Más allá del interés por los productos andinos en la actualidad, ¿cuáles han sido y son las condiciones en las cuales se realiza su producción en la Quebrada de Humahuaca? Las actividades agropecuarias cumplieron un rol central en las formas de reproducción de la población quebradeña a lo largo de su historia: una gran diversidad de maíces, tubérculos y otros productos típicos del área andina (como quinoa, yacón, amaranto) han sido reproducidos y traspasados de generación en generación. Esa riqueza agrícola se ha ido perdiendo con el tiempo. En particular algunos procesos que se desarrollaron durante el siglo XX, como la inserción de la población campesina al mercado laboral, la emigración rural asociada a ello y la expansión de la horticultura comercial, condujeron a una progresiva disminución de la producción agropecuaria tradicional y a la pérdida de la variedad de especies locales. Un proceso similar se manifiesta en relación a las comidas típicas de la población local que se fueron reemplazando por otro tipo de productos que se adquirían en el mercado (Arzeno, 2008) ${ }^{24}$.

\footnotetext{
24 Por ejemplo, un productor de Maimará señala al respecto de esos cambios: "[Mis padres y abuelos cultivaban] el maíz, el trigo y la papa. Eso era lo que ellos más cultivaban y les servía a ellos para poder pasar todo el año, porque antes no se compraba como es ahora toda la comida, no había tanto el fideo, el arroz... todo se hacía aquí, el fangollo, el maíz pelado, lo hacían el mismo maíz, la papa y después la crianza de animales pequeños y grandes para poder pasar el invierno... Y con eso se pasaba, muy poco era el gasto así como se ve ahora de dinero, hoy no hay 10 pesos no se come. Antes se comían la reserva de ciertos alimentos que uno podía pasar, digamos, 3 ó 4 meses sin gastar un centavo, porque tenía la carne, tenía toda la mercadería principal que producían en el mismo lugar" (entrevista personal, 2001).
} 
Hacia la década de 1990, la situación económico-social de la Quebrada se modifica. La modernización y/o cierre de varias de las fuentes de trabajo en las que se insertó parte de la población campesina local generó una migración de retorno de ex -productores que retomaron la producción agropecuaria, ya sea para autoconsumo o para la venta. En ambos casos se encontraron con distintas dificultades para producir y comercializar los cultivos: deterioro de la infraestructura de riego, la proliferación de plagas, ausencia de mercados para la colocación de los productos tradicionales, disminución de los precios y de la demanda de productos hortícolas e incremento de los costos de producción (Arzeno, 2008).

En este contexto desfavorable, caracterizado además por la existencia de altos índices de desocupación y pobreza, se inicia a mediados de la década de 1990 un proceso de intervención en materia de desarrollo rural de parte de organismos públicos de orden nacional y de algunas ONG locales ${ }^{25}$. A partir de ese momento, recursos económicos y asistencia de todo tipo comienzan a dirigirse hacia la población campesina quebradeña (Arzeno, 2007).

El principal resultado de este proceso de intervención fue el surgimiento y consolidación de numerosas organizaciones de pequeños productores. Bajo distintas formas jurídicas, aunque predominantemente organizadas como comunidades aborígenes, numerosas familias campesinas comienzan a recibir recursos económicos y asistencia para atender diversas cuestiones (productiva, educacional, de comunicación, de infraestructura, de salud, etc.) Pero en particular se destaca el intento por recuperar y mejorar la producción de cultivos andinos con el objetivo de comercializarlos, aprovechando la creciente demanda existente.

Es justamente esto último lo que se presenta como un eje en torno al cual estructurar

\footnotetext{
25 En el marco de políticas de ajuste, exclusión social y desaparición del Estado de muchas de sus esferas de intervención, se crean programas nacionales destinados a los sectores empobrecidos del ámbito rural, que a través de la articulación con las ONG, buscaban realizar una transformación productiva y mejorar sus ingresos.
}

una estrategia de "desarrollo local" desde las organizaciones de base y las organizaciones de apoyo. En este proceso de recuperación de semillas y mejoramiento de los cultivos tradicionales tuvieron (y tienen) un rol central los técnicos de distintos organismos o programas públicos y de las ONG, en su mayoría provenientes de otros lugares del país.

De particular relevancia resulta la experiencia de recuperación de la producción tradicional que vienen realizando algunas organizaciones, como la Red Puna y la Cooperativa Agropecuaria y Artesanal Unión Quebrada y Valles (CAUQueVa), ambas creadas a mediados de la década de 1990.

En el caso de la Red Puna (una organización que nuclea a 35 organizaciones de base y una ONG de desarrollo) se viene trabajando en el mejoramiento del cultivo de papa andina, pero también en la producción de carnes, especialmente de llama, que tiene una demanda creciente. Estas acciones, sin embargo, se encuentran enmarcadas en un proyecto más amplio y a más largo plazo, de tipo político, que busca revertir los problemas estructurales de la región, entre otros, el problema del acceso legal a la tierra, alineándose de esta manera con muchas de las demandas y acciones que Ilevan adelante organizaciones campesinas e indígenas del país. Como expresaron dirigentes de la Red:

\footnotetext{
"Queremos vivir con dignidad en nuestra tierra. Vivimos del trabajo de la producción y el esfuerzo diario, producimos alimentos para nuestras comunidades, para los pueblos y las ciudades, somos parte de la tierra, el agua y las semillas, somos vida y cultura. Sin embrago al día de hoy no nos han sido entregadas nuestras tierras comunitarias. Es por ello que la lucha por la Soberanía Alimentaria y por el territorio ha impregnado la dinámica de nuestra organización, y el compromiso" (La Hora de Jujuy, 7/4/2010).
}

Es decir que la recuperación de la producción local, más allá del aspecto económico, forma parte de una reivindicación política, social y cultural más amplia de parte de un sector de la sociedad quebradeña que ha sufrido procesos de dominación, explotación y marginación desde la colonia y que en el 
contexto actual encuentra un espacio para reclamar por sus derechos como trabajadores de la tierra.

CAUQueVa, por su parte, es una organización que nuclea a 150 socios de toda la Quebrada, centralmente dedicada en la actualidad a la recuperación, mejoramiento y comercialización de productos andinos. En este caso también el rescate de saberes locales se torna el eje estructurante de un proyecto estratégico a futuro para la población campesina quebradeña. Tal como se menciona en su página web, el objetivo de esta cooperativa es el de:

"elevar el nivel de vida de sus socios, a partir de la producción y comercialización tanto de sus productos ancestrales como de productos fruti hortícolas. Además ha tomado en sus manos, tareas de formación y capacitación como forma de re-valorizar técnicas antiguas de producción, sus propios productos, su alimentación y a través de ello la propia dignidad humana de los habitantes de la Quebrada de Humahuaca en la Provincia de Jujuy" (http://www.cauqueva.org.ar).

Cabe destacar en esta cita cómo se hace referencia a una de las principales cualidades de la producción local que comercializa la cooperativa, cuya sola mención agrega valor: en particular la cuestión de la ancestralidad y el "saber hacer" propio de los campesinos quebradeños (las técnicas antiguas). Por otro lado, apela al compromiso del consumidor que con su compra contribuye a la "dignidad humana" de la población local (es decir, al consumo responsable) ${ }^{26}$.

${ }^{26}$ Esta es una de las estrategias de venta de la cooperativa. Al respecto, su coordinador menciona, haciendo referencia a la venta domiciliaria en Buenos Aires que realizaron entre 2002 y 2004, que: "Lo que plantea la propuesta de la venta domiciliaria es el consumo solidario de productos de la Quebrada de Humahuaca. [...] Cuando la gente lo agarra por el lado del consumo solidario, no te puede decir, 'no, Quinta Fresca [una empresa de venta domiciliaria de hortalizas de Buenos Aires] lo vende más barato'. Los otros productos pueden bajar el precio pero la cooperativa no. Lo sacan de la competencia y lo plantean como algo de solidaridad y responsabilidad con la preservación del medio ambiente. Eso
Estas dos organizaciones, además, vienen intentando desarrollar algunos canales "alternativos" de comercialización, básicamente "cadenas cortas de distribución" que acercan a los productores con los consumidores finales del producto, tales como la venta directa al público en locales propios (como el que tiene la Red Puna en la capital provincial para vender carne de Ilama, cabrito, cordero, papas andinas, quinoa y quesos), o algunas exportaciones a Europa (como la que realizó CAUQueVa a través del movimiento Slow Food en el 2004) o la participación en eventos en los que buscan promocionar sus productos (como la feria anual Caminos y Sabores o la Feria de Mataderos, ambas en la ciudad de Buenos Aires, donde suelen tener un local de ventas CAUQueVa y la Red Puna, respectivamente). Se trata de alternativas que buscan alcanzar mercados más redituables en el nuevo contexto de revalorización de lo andino. Asimismo, intentan aprovechar aquellas posibilidades que surgen a partir del boom turístico. Por ejemplo, CAUQueVa instaló un Museo de la Vida Campesina que permite otra forma de promoción de la cooperativa y sus productos, apelando a la revalorización de la vida campesina típica de la Quebrada ${ }^{27}$.

Además de estas dos organizaciones de cierta antigüedad, a partir de la década de 2000 surgieron otras que tienen entre sus principales acciones la recuperación de cultivos andinos, entre ellos el yacón o la quinoa, que prácticamente habían desaparecido del ámbito de la Quebrada. Es el caso de la Cooperativa de Productores de Yacón de Chorrillos que, con apoyo del movimiento Slow Food, produce y comercializa una serie de productos derivados de ese cultivo como escabeche, jalea, té, hebras y caramelos (http:// www.yacon.org.ar).

pegó..." (entrevista al Coordinador de CAUQueVa, 2002).

27 "El Museo de la Vida Campesina tiene como objetivo la revalorización de lo propio, lo campesino. Contiene herramientas, colección de yuyos con los que curan, semillas, piezas de cocina, cántaros para la elaboración de chicha [...] [Y tiene por objetivo también] presentarle al turismo un mundo que no es conocido: presentarlo como parte de la vida local, dado que la propuesta turística no tiene en cuenta lo campesino" (entrevista al coordinador de CAUQueVa, 2005). 
Este proceso abrió un importante campo de intervención en el que participan, además, múltiples y diversos actores de "fuera" del lugar: desde el BID que financia a CAUQueVa, hasta la Fundación Monsanto que financia un proyecto del INTA sobre mejoramiento de papa andina, el Fondo para el Medio Ambiente Mundial y el PNUD que Ilevaron adelante un proyecto de recuperación de cultivos y comidas andinas, o la Agencia de Cooperación Española, que financió la creación de una cooperativa que produce alimentos locales deshidratados, entre otros (Arzeno y Troncoso, 2010: 234).

Además de la participación de organizaciones internacionales en este proceso de recuperación de la producción andina, cabe destacar un renovado interés de parte del gobierno provincial en el tema, que redunda en la formulación de algunos planes de apoyo al sector. Esto resulta inédito en la medida en que la zona de la Quebrada tuvo un lugar marginal en el desarrollo provincial, que históricamente privilegió, en particular, a las actividades agroindustriales del sur de la provincia. En este nuevo escenario surgen algunas iniciativas gubernamentales en la materia, aunque estas no alcanzan la magnitud que ha alcanzado la política específicamente orientada al desarrollo del turismo ${ }^{28}$.

En síntesis, la producción agrícola y ganadera local, en especial los productos andinos, son revalorizados en un nuevo contexto, de manera tal que se convierten en productos de alto valor en el ámbito local en que se pro-

\footnotetext{
${ }^{28}$ En ocasión de un evento sobre saberes de los pobladores andinos, el titular del Ministerio de la Producción de la provincia hizo referencia a: "la mirada del Estado que promueve ejes de desarrollo endógeno con sus propios circuitos locales que generan estabilidad a la hora de la seguridad y la soberanía alimentaria. Afirmó que el Gobierno de la Provincia de Jujuy, a través del Ministerio de la Producción, está realizando el Plan Estratégico de Producción Sustentable y este encuentro es parte de ese proceso, un plan que tiene dos formas de abordaje: el lado conceptual del plan en sí mismo y por otro lado el abordaje desde abajo, desde los orígenes" (La Voz del Cerro, 10/11/2010). Asimismo, en julio de 2010, los representantes por la provincia de Jujuy en el Senado de la Nación elevaron dos proyectos de ley para la promoción de los cultivos andinos, apelando a su importancia para el desarrollo de las regiones productoras.
}

ducen, en comparación con las otras producciones. Su "valor agregado" radica en ciertos aspectos asociados a la calidad del producto, que van más allá de cualidades intrínsecas (por ejemplo, nutritivas y de sabor) y que hoy son valorizadas por cierto grupo de consumidores: su especificidad geográfica, su carácter cultural y "patrimonial". Este aspecto es una "bandera" de las organizaciones de base para promocionar su producción, conseguir financiamiento y acceder a nuevos mercados.

Sin embargo, las posibilidades de inserción en esos nuevos mercados de manera estable son aún escasas debido a dificultades para: (i) conseguir las certificaciones necesarias (por ejemplo, que garanticen el origen y cualidades de los productos); (ii) generar canales alternativos de comercialización y sostenerlos en el tiempo; (iii) producir mayores volúmenes debido a los problemas existentes en relación con los sistemas de riego y las plagas; (iv) y en el caso de los productores hortícolas, realizar una reconversión productiva hacia las producciones tradicionales en la medida en que existe una alta dependencia de esa producción para la subsistencia de las familias y no están dadas las condiciones que garanticen la "sostenibilidad" de esos nuevos mercados que se abrieron.

A pesar de estas dificultades, la producción de cultivos andinos típicos sigue siendo una de las apuestas de varios de los productores organizados en la Quebrada, con vistas a satisfacer una demanda especialmente interesada en estos productos.

\section{Construcción y valorización de lugares: alimentos y nuevas prácticas turísticas en la Quebrada de Humahuaca}

En los puntos anteriores se analizó el proceso reciente de valorización de la especificidad geográfica de la Quebrada en el marco de las nuevas formas de producción y consumo de alimentos y las nuevas prácticas turísticas asociadas a ellas. Interesa aquí retomar este análisis a la luz de algunos desarrollos teóricos en torno al concepto de lugar que en las últimas décadas se han generado desde la Geografía. En particular queremos destacar la 
concepción del lugar como proceso, es decir, construido a partir de una trama de relaciones sociales en un locus determinado, cuya especificidad se define, entre otras cosas, por la forma distintiva y particular en las que relaciones sociales locales y otras más amplias se entremezclan, produciendo efectos (materiales y simbólicos) que pueden no darse en otros lugares (Massey, 1991).

En este sentido hablar de la construcción de una Quebrada agraria y turística es hacer referencia a este lugar como resultado (y condición necesaria) de un proceso que le imprime una nueva significación y expresión material y simbólica en el contexto actual. Esto es posible a partir de la existencia de mecanismos específicos y actores particulares que comandan, impulsan o participan de manera diferencial en este proceso.

En lo que sigue, entonces, reflexionamos sobre el proceso de construcción de la Quebrada como lugar agrario y turístico a la luz de estas conceptualizaciones que buscan comprender los procesos de construcción de lugar en sus múltiples dimensiones: lo local vinculado a lo global, la trama de actores que tienen injerencia en lo que sucede en el lugar y los planos material y simbólico en los procesos de construcción y transformación de los lugares.

a) En primer lugar, el proceso de valorización turística y agraria de la Quebrada de Humahuaca se comprende teniendo en cuenta los procesos globales que convocan e incentivan la competencia de lugares los cuales, reforzando la diferencia, ofrecen sus especificidades para atraer turistas, inversiones, recursos económicos, etc. En este sentido, la concepción del lugar como estrechamente vinculado con el "afuera" (es decir, el afuera como parte constitutiva del lugar y que define su especificidad; Massey, 1991) resultan centrales para comprender las transformaciones analizadas.

En efecto, tal comprensión se enriquece si se relaciona lo que acontece en la Quebrada con los procesos más amplios que han sido abordados en el trabajo: el rechazo a los sistemas de producción de alimentos deslocalizados y la valorización de aquellos asociados a un lugar; la condición de patrimonio con que fuertemente se cargan productos o preparaciones que consecuentemente requieren un tratamiento de protección y que se asumen también como elementos más auténticos y de calidad; la revalorización en general de los ámbitos rurales y todos los aspectos a ellos asociados que se asumen en peligro de extinción por el avance de la modernidad; la valorización de culturas no occidentales y sus manifestaciones y conocimientos ancestrales que justifican acciones en pos de su protección, etc. La Quebrada responde a todos estos aspectos para satisfacer las demandas que ellos involucran $y$, en definitiva, participa de los procesos de creación y reforzamiento de la diferencia (Ilbery \& Kneafsey, 1998; Feagan, 2007) geográfica, cultural, técnica, que va a orientar las formas actuales de producción y consumo.

Asimismo, la construcción de la Quebrada como un lugar agrario tradicional y como lugar turístico también se comprende por decisiones de la política nacional y acontecimientos específicos a esa escala. En efecto, las políticas orientadas a brindar asistencia a los pequeños productores surgidas en la década de 1990, el impulso al turismo en la década posterior, el incentivo reciente a la valorización turística del patrimonio por parte del gobierno provincial constituyen elementos que explican también estas transformaciones quebradeñas y que van a dar forma a las especificidades del proceso de construcción de este lugar particular.

b) La construcción de un lugar turístico y agrario puede comprenderse como resultado de un proceso que involucra diversos actores con sus intenciones, intereses, acciones específicas y relaciones que establecen entre sí, mediadas por las diferentes cuotas de poder que detentan. Es justamente esa particular constelación de relaciones sociales, de acuerdo con Massey (1991), la que constituye al lugar, le otorga especificidad y define su esencia dinámica y cambiante.

Dentro del conjunto de actores que interviene en los procesos de construcción y 
transformación de un lugar, hay algunos que resultan dominantes en determinados momentos. En el caso analizado, de hecho, quienes lideraron el proceso de construcción de una Quebrada agraria y turística basada en la puesta en valor de especificidades que responden a las nuevas formas de consumo turístico y de alimentos, son actores que no tienen una vinculación tradicional con el lugar (en el sentido que no lo consideran un referente identitario). Son ellos quienes cuentan con información central acerca de las nuevas demandas. Entre estos actores se encuentran técnicos agrarios, empresarios gastronómicos y turísticos en general, turistas, chefs y expertos de organizaciones internacionales encargadas del financiamiento de experiencias de estímulo a la producción de cultivos tradicionales. Esto no significa que la población quebradeña no esté interesada o no participe de estos procesos. De hecho, los actores externos se articulan con otros que se reconocen como pertenecientes al lugar, entre ellos, los productores (generalmente aquellos que conforman organizaciones) y algunos emprendedores turísticos originarios de la Quebrada que comercializan productos alimenticios. Pero los impulsos iniciales tienen como importantes protagonistas a actores que podría decirse que se acercaron a la Quebrada con una mirada foránea. Así, en cierta medida, estos procesos de valorización de la Quebrada están organizados en función de intereses externos al lugar.

Sin embargo, más allá de quienes fueron los impulsores de estos procesos, la participación de la población local es diferencial, en la medida en que es más incluyente en el caso de la valorización agraria de la Quebrada (los productores campesinos tienen al menos una participación más directa), no así en el caso de la valorización turística, dado que sus principales beneficiarios son empresarios provenientes de otros lugares.

c) En el proceso de construcción de un lugar pueden reconocerse dimensiones materiales y simbólicas (Agnew, 1987: Massey, 1995). Atendiendo a la dimensión material del lugar, los procesos recientes dan cuenta de una transformación marcada por la reformulación de las áreas de producción (qué se cultiva en ellas, con qué técnicas, cómo se destinan espacios para la experimentación con los nuevos cultivos) dando cuenta de una estrategia orientada a aprovechar un contexto de nuevas demandas específicas. Asimismo, la Quebrada se transforma en función del turismo: nuevos emprendimientos, muchos de ellos gastronómicos o donde la gastronomía tiene un lugar esencial, han cambiado la fisonomía de los pueblos quebradeños para satisfacer las demandas de turistas, exigentes consumidores de productos tradicionales, auténticos, ancestrales, etc.

Al analizar los significados otorgados al lugar, la dimensión simbólica de este proceso de construcción de la Quebrada como un lugar turístico y agrario, la asociación comida-cultura-lugar tiene un papel central. El lugar, la Quebrada, en todas las dimensiones otorga especificidades a los productos andinos que los hacen diferentes y competitivos en el mercado de specialities. Así, el lugar le otorga valor agregado a estos productos en un contexto en el cual el origen (geográfico, cultural) de lo que se consume importa más que nunca (Cook \& Crang, 1996; Ilbery \& Kneafsey, 1998). En el caso de la Quebrada, esta asociación alimento-cultura-lugar se refuerza en varios sentidos: las condiciones físico-naturales de la Quebrada se asumen como otorgando especificidades a los productos (el clima seco y de altura que permite el cultivo de especies y variedades vernáculas, el sol que ayuda a obtener los productos deshidratados al aire libre, la sal de las salinas cercanas que se comercializa saborizada, etc.); el conocimiento y las técnicas asumidas como un patrimonio que se mantiene en el tiempo pasando de generación en generación también aparecen dotando de particularidades a los productos (el saber hacer es custodiado por la población tradicional quebradeña).

Pero a su vez estos productos refuerzan las especificidades que la Quebrada tiene como lugar turístico (los alimentos forman parte de la atractividad del lugar) y como 
lugar agrario (en tanto ciertas tradiciones productivas históricas asociadas al lugar son las que efectivamente se rescatan para dar forma a una nueva estrategia económica). En relación con esto, la asociación lugar-comida-cultura define (y es definida por) (i) la creación de representaciones y formas concretas de organización de este lugar para el turismo (en la medida en que constituyen formas de consumo atentas al origen geográfico o cultural andino de los bienes asociados al lugar) y (ii) la revitalización de formas de producción asumidas como tradicionales de la Quebrada, donde los alimentos locales formarán parte del conjunto de elementos a los que los productores recurren para dar cuenta del acervo de tradiciones que los aglutina y le otorgan identidad para acompañar sus reivindicaciones políticas, económicas, sociales y culturales.

\section{Reflexiones finales}

La actual promoción del consumo de productos andinos se enmarca en procesos más amplios de valorización de alimentos a los que se atribuye un contenido geográfico y cultural que les agrega valor y distinción y que los diferencia dentro del mercado agroalimentario. Ciertos grupos de consumidores contribuyen a la generación de nuevos mercados en torno a estos productos.

Por su parte, los productos y culinaria andina pasan a constituirse en un atractivo que responde también a las nuevas formas de consumo turístico, contribuyendo a la construcción de un imaginario geográfico que acompaña la promoción, en este caso de la Quebrada, como destino "exótico" y fuera del circuito de turismo masivo.

Asimismo, lo anterior abre un escenario que desde la política pública, el sector empresarial, los pequeños productores y organizaciones de apoyo se intenta aprovechar $y$ que se enmarca en el discurso del desarrollo local o territorial al cual cada sector (en función de sus intereses) otorga significados distintos, para promover o justificar acciones específicas.

Como vemos, todos estos procesos confluyen en el lugar (la Quebrada) como ámbito que cobra nueva significación en el contexto nacional y global y que gana "competitividad" en función de la valorización de algunos de sus atributos reconocibles por ciertos sectores. Pero la multiplicidad de actores e intereses que intervienen en esta construcción de una Quebrada ahora "competitiva", nos conduce a preguntarnos ¿cuánto de esta nueva promoción de los productos andinos redunda en una mejora de las condiciones de vida de quienes son en definitiva los que le otorgan el contenido cultural que hoy se valoriza?

La propuesta analítica presentada en este trabajo ha estado guiada por conceptualizaciones recientes que permiten tener en cuenta los múltiples procesos comandados desde distintas localizaciones (global, nacional, provincial) y los variados actores que tienen diversas formas y capacidad de injerencia sobre lo que acontece en el lugar. Esta perspectiva, creemos, permite una mejor comprensión de la complejidad de los procesos implicados en la construcción de la nueva Quebrada agraria y turística y su seguimiento, seguramente, permitirá continuar indagando sobre estas cuestiones.

\section{Referencias bibliográficas}

AGNEW, J. Place and politics. The geographical mediation of state and society. Boston: Unwyn Hyman, 1987.

ÁLVAREZ, M. (compilador). Las cocinas andinas en el Plata. Biodiversidad, cultura y gastronomía. Buenos Aires: La Crujía Ediciones, 2008.

ÁlVAREZ, M. y SAMMARTINO, G. Empanadas, tamales y carpaccio de Ilama. Patrimonio alimentario y turismo en la Quebrada de Humahuaca - Argentina. Estudios y perspectivas en turismo, 2009, Vol. 18, p. 161-175.

ARMESTO LÓPEZ, X. y GÓMEZ MARTÍN, B. Productos agroalimentarios de calidad, turismo y desarrollo local: el caso del Priorat. Cuadernos geográficos, 2004, No 34, p. 8394.

ARZENO, M. Procesos organizativos en la Quebrada de Humahuaca. El caso de las organizaciones de base. En: MANZANAL, M.; 
ARZENO, M. y NUSSBAUMER, B. (compiladores). Territorios en Construcción. Actores, tramas y gobiernos: entre la cooperación y el conflicto. Buenos Aires: Ediciones CICCUS, 2007, p. 197-224.

ARZENO, M. Pequeños productores campesinos y transformaciones socioespaciales. El cambio agrario en la Quebrada de Humahuaca (Jujuy). Buenos Aires: Tesis de Doctorado, Facultad de Filosofía y Letras, Universidad de Buenos Aires, 2008 (inédito).

ARZENO, M. y TRONCOSO, C. Actividades agrarias, turismo y contradicciones del desarrollo en la Quebrada de Humahuaca, Jujuy. MANZANAL, M. y VILLARREAL, F. (coordinadores). El desarrollo y sus lógicas en disputa en territorios del norte argentino. Buenos Aires: Ediciones CICCUS, 2010, p. 223-246.

BÉRARD, L.; CONTRERAS, J. y MARCHENAY, P. Presentación. Agricultura y Sociedad. Buenos Aires: monográfico: Los productos de la tierra, 1996, $\mathrm{N}^{\circ} 80-81$, p. 13-27.

BESSIÈRE, J. Local development and heritage: traditional food and cuisine as tourist attractions in rural areas. Sociologia Ruralis, 1998, Vol. 38, Nº1, p. 21-34.

CARTA ABIERTA JUJUY. Para paladares exigentes, febrero-marzo 2004.

CARTA ABIERTA JUJUY. Un encuentro irresistible con la mesa quebradeña, febreromarzo de 2006.

COOPERATIVA AGROPECUARIA Y ARTESANAL UNIÓN QUEBRADA Y VALLES, Disponible en Internet: http://www.cauqueva. org.ar

CAUQUEVA. Folleto del Museo de la Vida Campesina, 2006.

CLARIN. Buscan revitalizar la cocina autóctona del noroeste del país, reportaje del 09/04/2005. Disponible en Internet: http://www.clarin.com/diario/2005/04/09/ sociedad/s-05601.htm

CLARIN. Con sabor andino, reportaje del 16/09/2007.
COOK, I. \& CRANG, P. The world on a plate: culinary culture, displacement and geographical knowledges. Journal of Material Culture, 1996, Vol. 1, № 2, p. 131-153.

CUISINE \& VINS. Cuisine Menú C\&V Lalo Angelina, Impulsor de la Cocina de Altura, reportaje de septiembre de 2005, p. 1-3.

EVERETT, S. Beyond the visual gaze: the pursuit of an embodied experience through food tourism. Tourist Studies, 2009, Vol. 8, No 3, p.337-358.

FEAGAN, R. The place of food: mapping out the 'local' in local food systems. Progress in Human Geography, 2007, Vol. 31, № 1, p. 23-42.

LARA FLORES, S. Nuevas experiencias productivas y nuevas formas de organización del trabajo en la agricultura mexicana. Ciudad de México: Juan Pablos Editor, 1998.

GERMANN MOLZ, J. Eating difference: the cosmopolitan mobilities of culinary tourism. Space and Culture, 2007, Vol. 10, № 1, p. 77-93.

GOBIERNO DE LA PROVINCIA DE JUJUY. Quebrada de Humahuaca. Un itinerario cultural de 10.000 años. San Salvador de Jujuy: Propuesta para la inscripción a la lista de patrimonio mundial, 2002.

GOODMAN, D. \& WATTS, M. Reconfiguring the Rural or Fording the Divide?: Capitalist Restructuring and the Global Agro-Food System. The Journal of Peasant Studies, 1994, Vol. 22, No 1, p. 1-49.

GUÍA TURÍSTICA YPF. Centro y noroeste. Santiago de Chile, 1998.

HARVEY, D. La condición de la posmodernidad. Investigación sobre los orígenes del cambio cultural. Buenos Aires: Amorrortu, 1998.

HOSTNEWS. Rëd Resto \& Lounge recibe en su cocina al reconocido chef Walter Leal, 2008. Disponible en Internet: http://www. hostnews.com.ar. 
HIDEAUT. Hostería Rincón del Fuego: gastronomía andina de altura, 2008. Disponible en Internet: http://www.hideout.com.ar/ default3.asp? $\mathrm{id}=346$

ILBERY, B. \& KNEAFSEY, M. Product and place: promoting quality products and services in the lagging rural regions of the European Union. European and Regional Studies, 1998, p. 399-341.

ILBERY, B.; MORRIS, C.; BULLER, H.; MAYE, D. \& KNEAFSEY, M. Product, Process and Place: an examination of food marketing and labeling schemes in Europe and North America. European Urban and Regional Studies, 2005, 12 (2), p. 116-132.

JUJUY ACTIVA TURISMO. Rescatar los sabores y valores de los cultivos andinos, 2007, $\mathrm{N}^{\circ} 1$.

LA GUÍA PIRELLI. Argentina, 1989. Buenos Aires: Pirelli Argentina S. A.

LA HORA DE JUJUY. XIV edición de la Feria del Cambalache y Trueque en Ocumazo, reportaje del 07/04/2010. Disponible en Internet: http://www.lahoradejujuy.com.ar

LA NACIÓN (a). Exquisiteces autóctonas, reportaje del 5/08/2007.

LA NACIÓN (b). Purmamarca con sabor a quinoa, llama y papines, reportaje del 5/08/2007.

LA VOZ DEL CERRO. Apertura del III Encuentro Internacional Saberes y Haceres de Pobladores Rurales Andinos, reportaje del 10/11/2010. Disponible en Internet: http:// lavozdelcerro.com.ar/?p=2193

Lugares, el manantial del silencio. Disponible en Internet: http://www.enjoy-argentina. org/revista-lugares/revista-lugares-el-manantial-del-silencio.php

MANZANAL, M. Territorio, Poder e Instituciones. Una perspectiva crítica sobre la producción del territorio. En: MANZANAL, M.; ARZENO, M. y NUSSBAUMER, B. (compiladores). Territorios en construcción. Actores, tramas y gobiernos, entre la cooperación y el conflicto. Buenos Aires: Ediciones CICCUS, 2007, p. 15-50.

MASSEY, D. A global sense of place. Marxism Today, 1991, p. 24-29.

MASSEY, D. A place in the world? Places, cultures and globalization. Oxford: Oxford University Press/ The Open University, 1995.

MAYE, D. \& ILBERY, B. Regional economies of local Food production. Tracing food chain links between 'specialist' producers and intermediaries in the ScottishEnglish borders. European Urban and Regional Studies, 2006, Vol. 13, No 4, p. 337 354.

MEETHAN, K. Tourism in global society. Place, culture, consumption, Nueva York: Palgrave, 2001.

MOREIRA BRAGA, T. Desenvolvimento Local Endógeno. Entre a competitividade e a Cidadania. Estudos Urbanos e Regionais, 2002, No 5, p. 23-37.

PARROT, N.; WILSON, N. \& MURDOCH, J. Spatializing quality: regional protection and the alternative geography of Food. European Urban and Regional Studies. 2002, Vol. 9, No 3 , p. 241-261.

PASOS. Revista de turismo y patrimonio cultural, 2008, Vol. 6, № 2. Número especial sobre Turismo gastronómico y enoturismo.

RENARD, M. C. Globalización y mercados de calidad: una vía para los pequeños productores. Cuadernos Agrarios, 1999, No 17-18, p. 76-93.

SCHLÜTER, R. Turismo y patrimonio gastronómico. Una perspectiva. Buenos Aires: CIET, 2006.

\section{SLOW ARGENTINA, 2006, Nº 3 .}

TÖREY, S. El valioso toque competitivo que otorga el 'alma de la gente'. Equitierra. Revista Rural Latinoamericana, 2010, №5, p. 14-20.

TRONCOSO, C. Creando un lugar turístico y patrimonial: las transformaciones en la 
Quebrada de Humahuaca a partir de los procesos de construcción de atractividad turística y patrimonialización. Buenos Aires: Tesis de Doctorado, Facultad de Filosofía y Letras, Universidad de Buenos Aires, 2008a (inédito).

TRONCOSO, C. Turismo, desarrollo y participación local. La experiencia de Quebrada de Humahuaca (Jujuy, Argentina). Revista Aportes y Transferencia, 2008b, Año12, Vol. 2, p. 110-130.

URRY, J. O olhar do turista. Lazer e viajens nas sociedades contemporáneas. São Paulo: SESC- Studio Nobel, 1996.
VALDERRAMA LEÓN, M. Gastronomía: nueva locomotora de desarrollo de Perú. Equitierra. Revista Rural Latinoamericana, 2010, N 5, p. 4-11.

WATTS, D, ILBERY, B. \& MAYE, D. Making reconnections in agro-food geography: alternative systems of food provision. Progress in Human Geography, 2005, № 29, p. 22-40.

WELCOME ARGENTINA. Más que cocina del norte. Disponible en Internet: http://www. welcomeargentina.com/paseos/masque_ cocina_delnorte/index.html 